\title{
A review of the MAFF Optimal Nutrition Status research programme: folate, iron and copper
}

\author{
$\mathrm{J}^{\text {Buttriss }}{ }^{1, *}$ and J Hughes ${ }^{2}$ \\ ${ }^{1}$ British Nutrition Foundation, 52-54 High Holborn, London WCIV 6RQ, UK: ${ }^{2} 7$ Holmesdale Park, Coopers Hill \\ Road, Nutfield, Surrey, RH1 4NW, UK
}

Submitted 22 January 2001: Accepted 5 December 2001

\begin{abstract}
Objective: The objective was to conduct a critical appraisal of research conducted within one of the UK government's research programmes, Optimal Nutrition Status, and to place the findings of this work in the context of the international research effort, to assist policy makers and advisers. Nine nutrients are addressed within the programme; the findings for three of these are reported here: folate/folic acid, iron and copper.

Design: To conduct the review, the researchers had access to all unpublished progress reports, submitted to officials, arising from the projects. The overall assessment criterion was whether the information generated by the research programme could be regarded as reliable experimental data of direct relevance to setting optimal dietary requirements for the particular micronutrients. However, findings were also assessed against specific scientific criteria concerning understanding of the bioavailability, interactions, development of functional markers and inter-individual variations in metabolism, for each of the nutrients scrutinised.

Results: The results of the review indicated that many important questions are indeed being addressed by the UK government's research programme, and that the work is contributing to the overall research effort being conducted world-wide on this important subject.

Conclusions: Many major questions still need to be addressed before it will be possible to identify optimal intakes for various sub-populations. These priorities are summarised in the paper.
\end{abstract}

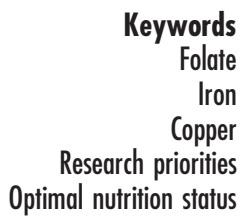

During the latter half of the twentieth century, much has been learned about mankind's nutritional requirements, but the main focus has always been on prevention of deficiency rather than optimisation of health. With increased understanding of the ways in which good nutrition can positively promote health, attention has been directed at identifying intake levels of micronutrients with the potential to optimise nutritional status and thereby provide a public health benefit.

The review of Dietary Reference Values (DRVs) ${ }^{1}$ acknowledged that claims have been made that high intakes of some nutrients may have beneficial or therapeutic effects, but the DRVs Panel decided that such effects did not fall within their definition of requirements. The Panel did, nevertheless, attempt to provide some guidance on the possible effects of very high intakes. More recently, optimisation of intake has been a focus of the recent series of reviews conducted in the United States, and published reviews now exist for calcium and other bone-related nutrients, antioxidant nutrients and $\mathrm{B}$ vitamins (www.nationalacademies.org). Also, in the UK, the Expert Group on Vitamins and Minerals, under the auspices of the Food Standards Agency (FSA), is systematically assessing reviews and risk assessments for a wide range of nutrients (details can be found on www.foodstandards.gov.uk). Although the Expert Group's remit largely concerns controls to ensure safety of vitamins and minerals, the reviews published provide a wealth of useful information.

During the past 10 years, the UK government has been funding a research programme to establish whether it is possible to identify optimal intakes of a number of micronutrients. The number of nutrients has risen to nine, although some receive more funding than others, and there are some obvious omissions from the list, such as zinc.

In April 1999, the British Nutrition Foundation was awarded a nine-month contract by the Ministry of Agriculture, Fisheries and Food (MAFF) to conduct a critical review of the research being conducted within MAFF's Optimal Nutrition Status research programme. The aim was to place this research within the context of other 
1. To understand the links between Optimal Nutrition Status and the maintenance of good health

\section{Develop accurate measure of} bioavailability from foods:

(i) measure the fraction of ingested

nutrients that meets functional

demands in target tissues

(ii) develop functional markers of status for each micronutrient or group of micronutrients

(iii) use human intervention studies to determine dose-response

relationships against tissue function
Two projects (AN0526, AN0534) are exploring the links between folate/folic acid intake, plasma homocysteine levels (as a functional marker of status) and cardiovascular function (vascular endothelial function as a specific tissue function), and whether the improvement in function, if any, is mediated by decreased oxidative stress, in parallel with its effect on lowering plasma homocysteine. These projects will also assess the extent to which individuals with an
inherited partial defect in MTHFR have an increased requirement for dietary folate to normalise homocysteine and inherited partial defect in MTHFR have an increased requirement for dietary folate to normalise homocysteine and
vascular endothelial function, and will provide experimental evidence to inform assessment of DRVs for folates In project AN0538, a stable isotope methodology for use in assessing the absorption and metabolism of folates has been developed, as has a gas chromatography-mass spectrometry method to measure individual folate concentrations in foods and biological samples. These methods have been used to assess the bioavailability of folic acid added to two in foods and bio, as has a cereal foods, compared with a capsule delivery method, in a group of women who have been fully characterised in terms of their folate intake, biochemical status and MTHFR genotype. This work has provided data on food matrix effects. The same investigators intend to build on this work by using stable isotopes to determine the difference in absorption of folic acid and a major natural food folate (5-formyltetrahydrofolic acid, 5-CHOTHF), and to determine if folic acid is more effectively absorbed and utilised than naturally occurring folates in vegetables (AN0550)

Another project (AN0546) is investigating the relative merits of natural food folates and food fortified with folic acid, with respect to ability to raise blood folate status and decrease plasma homocysteine. Bioavailability of folic acid in flour and folates in three different types of food folate extract, as well as in a food matrix, will be investigated

Three separate projects (AN0526, AN0534 and AN0546) are using plasma homocysteine level as a functional marker of folate status relevant to cardiovascular disease. One of these (AN0526) is evaluating a marker of endothelial cell damage as a functional indicator of homocysteine-related risk in relation to cardiovascular function

All of the projects in the folates programme contain intervention studies. One project (AN0526) includes two intervention studies: study A is investigating the question 'Does nutritional intervention to increase folate status improve vascular studies: study A is investigating the question 'Does nutritional intervention to increase folate status improve vascular endothelial function?' and study B (135 subjects) is investigating the relative merits of natural food folates and food
fortified with folic acid with respect to ability to raise blood folate status and decrease plasma homocysteine. Study A will include 42 subjects each of the CC/CT/TT MTHFR genotypes. Study A has a crossover design with 4-month interventions and three conditions: control (approx. $200 \mu \mathrm{g} \mathrm{day}^{-1}$ ), combined fortified and natural food folates (approx. $400 \mu \mathrm{g} \mathrm{day}^{-1}$ ) and control plus $400 \mu \mathrm{g}_{\text {day }}{ }^{-1}$ folic acid supplement (approx. $600 \mu \mathrm{g} \mathrm{day}^{-1}$ ). The effect of the dietary intervention on homocysteine and vascular endothelial responses will be assessed. Study B has a parallel groups design with 4-month interventions and three conditions: control (approx. $200 \mu \mathrm{g} \mathrm{day}^{-1}$ ), natural folate group (increased intake by $100 \mu$ day $^{-1}$ by eating extra folate-rich foods by $100 \mu{ }^{-1}$ dation (plasma and red cell) and homocysteine concentrations will be assessed. A related collaborative project is investigating the role of oxidative stress in homocysteine-induced vascular dysfunction

Another project (AN0546) includes several intervention studies in healthy men aged 18-45 years. The first study aims to confirm a quantitative response of the functional marker plasma homocysteine to differential levels of synthetic folic acid. Subsequent interventions will measure the bioavailability of folate in a flour matrix in comparison with a folic acid regimen ('gold standard'); the bioavailability of food folates at comparable levels of folic acid; the bioavailability of food folates at increased levels of folic acid; and finally the bioavailability of food folate from a natural unbroken matrix

Yet another intervention study (AN0550) will measure relative absorption of intrinsically labelled food folates compared with folic acid

Two projects (AN0526, AN0534) are exploring the extent to which individuals with an inherited partial defect in MTHFR ( $10 \%$ of the population) have an increased requirement for dietary folate to normalise plasma homocysteine and vascular endothelial function of inter-individual variations, so as to identify an optimal nutrient intake for the whole population

AN0526 - Dietary folate, homocysteine and endothelial function: a study of the interaction with methylenetetrahydrofolate reductase genotype. University Hospital of Wales, Cardiff, 1997-2000 (Food Standard Agency project reference N05002).

AN0534 - Dietary folate, homocysteine and endothelial function: the potential role of oxidative stress in vascular damage. University of Sheffield, 1999-2000 (Food Standards Agency project reference N05006). AN0538 - Quantitative studies on the bioavailability of folates in food using isotope ratio (dilution) mass spectrometry. Institute of Food Research (IFR) Norwich, $1995-1998$.

ility of folic acid and natural folates: studies using the functional marker plasma homocysteine. University of Ulster, 1998-2001 (Food Standards Agency project reference N05013).

AN0550 - Is folic acid considerably more effective than folates in raising folate status? IFR Norwich, 1998-2001 (Food Standards Agency project reference N05016). 
relevant work being conducted nationally and internationally, to produce a list of future research recommendations to aid policy makers and advisors and, not least, to disseminate the findings to a wide audience.

MAFF's Optimal Nutrition Status Research Programme began in 1991 and, to date, over 40 research projects have been funded. The majority of these are concerned with one or more of the following nutrients: iron, copper, selenium, vitamin $\mathrm{E}$, vitamin $\mathrm{C}$, calcium, vitamin $\mathrm{D}$, vitamin $\mathrm{K}$ and folate/folic acid. To conduct the review, the nutrients were grouped together in terms of aspects of function.

This paper constitutes a summary of the findings of the review for folate/folic acid, copper and iron. The structure of the review is described elsewhere ${ }^{2}$, and detailed summaries of the findings for these and other individual nutrients have been published ${ }^{3-5}$.

\section{Objectives of the programme}

MAFF describes two main scientific objectives for the Optimal Nutrition Status programme. The first objective is the need to understand the links between Optimal Nutrition Status and the maintenance of good health. Within this objective is the priority to understand the potential interactions between micronutrients at different stages in life in the reduction of specific disease. The second objective is the need to develop accurate measures of bioavailability from foods, using studies in the whole body to take account of the potential interactions between nutrients at the gut level, and the effective transport of these nutrients to where they are needed. Within this second objective, four specific sub-objectives can be defined: (i) measure the fraction of ingested nutrients that meet functional demand in target tissues; (ii) develop functional markers of status for each micronutrient, or group of micronutrients; (iii) use human intervention studies to determine dose-response relationships against tissue function; and (iv) understand the nature and extent of inter-individual variations, so as to identify an optimal nutrient intake for the whole population.

MAFF's overall criterion to be used in evaluating the programme is whether it generates reliable experimental data of direct relevance to setting dietary requirements for those micronutrients that are assessed by expert committees, such as the former Committee on Medical Aspects of Food and Nutrition Policy (COMA).

\section{Folate/folic acid}

Five MAFF-funded projects focus on folate/folic acid. The achievements of these in relation to the programme objectives can be found in Table $1^{6-19}$.

Folate is the umbrella term used to describe natural food folates and synthetic folic acid. These share the same vitamin activity, although the bioavailability of folic acid is currently thought to be greater than (about double) that of the naturally occurring forms. Folic acid is the form used in supplements and to fortify foods such as bread and breakfast cereals ${ }^{20}$.

Folate is found naturally in green leafy vegetables but other vegetables and fruits, e.g. broccoli, cauliflower, parsnips and oranges, are useful sources. In addition, liver, yeast, yeast extract and beer are good sources.

The current average intake of folates in the UK is about $250 \mu \mathrm{g} \mathrm{day}^{-1}$, about two-thirds of which is provided by cereal foods and vegetables. The average intake in women of childbearing age is slightly lower at about $200 \mu \mathrm{g}$ per day $^{20}$, based on the findings of national surveys ${ }^{21,22}$.

The biochemical role of folate is in the interconversion of one-carbon units in intermediary metabolism; a process in which a methyl group is formed de novo. The methyl group is subsequently transferred to $S$-adenosylmethionine (SAM), which is an activated form of methionine that serves as a methyl donor to a whole range of methyltransferases. These enzymes methylate a wide range of substrates including $\mathrm{DNA}^{23}$. This process also results in the formation of $S$-adenosylhomocysteine (SAH), which is immediately enzymatically hydrolysed to homocysteine. Homocysteine can be degraded or catabolised by means of a trans-sulphuration pathway via cystathionine to cysteine and eventually to sulphate and pyruvate, which can be utilised to provide energy. Alternatively, the carbon-sulphur structure of homocysteine can have a methyl group added, which converts it to methionine and preserves it within the cells. In humans the liver and kidney can also use betaine, a breakdown product of choline, to convert homocysteine to methionine. This recycled methionine can then be activated by adenosine triphosphate (ATP) to produce another SAM, which is again available to a methyltransferase to methylate another protein or phospholipid (the methylation cycle). The cycle has methyl groups supplied to it via the folate cofactor 5methyltetrahydrofolate (5-MTHF), this being formed by the enzyme methylenetetrahydrofolate reductase $(\mathrm{MTHFR})^{24}$.

The relationship between sub-optimal folate status and the occurrence of neural tube defects in utero is now well established. The recent review of folic acid by the UK COMA committee ${ }^{20}$ reaffirmed the advice that women of childbearing age in the UK should take a daily folic acid supplement $(400 \mu \mathrm{g})$, bringing their daily intake of folates to an average of $600 \mu \mathrm{g} \mathrm{day}^{-1}$. The mechanism for this benefit still needs to be established.

The interrelationship of folate and vitamin $\mathrm{B}_{12}$ in the regeneration of tetrahydrofolate in the homocysteine cycle is also relatively well characterised. Research is now focusing on the generation of homocysteine itself and the importance of circulating levels of this metabolite as an independent risk factor for cardiovascular disease ${ }^{25}$.

Plasma homocysteine is inversely related to dietary folate over the range of intakes found in the general population $\left(200-400 \mu \mathrm{g} \mathrm{day}^{-1}\right)^{26}$. Furthermore, evidence 
exists to suggest that a raised plasma homocysteine concentration is a predictor of cardiovascular risk ${ }^{20,23}$. However, evidence from randomised intervention trials is yet to be published, and this situation prevented COMA from being able to offer advice on the value of dietary folic acid supplements for people at risk of heart disease. COMA did, however, acknowledge the importance of a diet rich in folate-containing foods.

Randomised evidence for the effects on vascular disease of dietary supplements of folic acid, with or without vitamin $\mathrm{B}_{6}$ or vitamin $\mathrm{B}_{12}$, should be available from several large-scale clinical trials involving 30000-40000 patients with prior coronary heart disease within 5 or 6 years ${ }^{27}$. There are seven current and planned clinical trials (two in the USA, two in the UK, two in Norway and one in Australia). The two in the UK - Study of the Effectiveness of Additional Reductions in Cholesterol and Homocysteine (SEARCH) based in Oxford, and the Cambridge Heart Antioxidant Study (CHAOS-2) - began in 1998. The dietary intervention in SEARCH is $2 \mathrm{mg}$ folic acid with $1 \mathrm{mg}$ $\mathrm{B}_{12}$ versus placebo for 12000 subjects, with a minimum follow-up of at least 4 years, and that in CHAOS-2 is $5 \mathrm{mg}$ folic acid versus placebo for 4000 subjects.

All seven trials have adopted similar endpoints, such as fatal and non-fatal coronary heart disease, haemorrhagic and other strokes, and total and site-specific cancers. This should enable the principal investigators in each trial to collate the individual participant data from their studies in a systematic overview of the post-publication follow-up of their separate results ${ }^{28}$. It is hoped that these trials will provide the necessary evidence to guide policy on the use of screening for homocysteine levels, the use of folic acid supplements in high-risk individuals, and the value of efforts to raise the mean plasma folate level of the population (by fortification) for protection against cardiovascular diseases.

There are a small number of studies that suggest a high folate intake is related to a reduced risk of certain cancers, e.g. colorectal cancer ${ }^{29}$ and breast cancer ${ }^{30}$, but so far this is inconclusive. Elevated plasma total homocysteine and low serum folate and vitamin $\mathrm{B}_{12}$ have also been found to be associated with Alzheimer's disease ${ }^{31}$.

Concern has been expressed about the possibility that unrestricted lifelong exposure to folic-acid-fortified foodstuffs might result in the presence of unmetabolised folic acid in the circulation, which has been linked with masking of the diagnosis of cobalamin $\left(\mathrm{B}_{12}\right)$ deficiency in pernicious anaemia and hence the progression of neurological disease; other effects are unknown ${ }^{32}$. Recent research designed to determine the threshold level, in chronically saturated subjects, above which unmetabolised folic acid begins to appear in the serum, after consumption of folic-acid-fortified bread, has been carried out by the same group. The results demonstrated that $200 \mu \mathrm{g}$ of folic acid in bread causes unmetabolised folic acid to appear in the serum post-prandially ${ }^{33}$.
The COMA committee ${ }^{20}$ used British food consumption data to estimate a level of fortification that would result in benefits to women of childbearing age but would not result in older people having intakes that could be regarded as disadvantageous with regard to vitamin $B_{12}$ deficiency. They arrived at the figure of $240 \mu \mathrm{g} / 100 \mathrm{~g}$ wheat flour in food products as consumed. (In the USA, fortification of all cereal flours, not just wheat, is already in place at the level of $140 \mu \mathrm{g} / 100 \mathrm{~g}$ flour.)

The COMA committee decided that there is currently insufficient new evidence to warrant a review of the present DRVs for folates, but that there is a need to address optimisation of intakes as soon as is practicable. That is, there is an urgent need for more evidence from research on interactions between folates and the aetiology of disease such as cardiovascular health and cancer.

\section{Contribution made by the MAFF programme}

As can be seen from Table 1, a number of the research questions referred to above are being addressed by projects funded within the MAFF programme. However, important questions still remain unanswered, and priorities were identified and submitted to MAFF as part of the work conducted by the British Nutrition Foundation (Table 2).

\section{Copper}

Table $3^{35-38}$ lists the projects concerning copper conducted within the MAFF programme and the contributions these projects have made to MAFF's programme objectives.

Copper has been recognised as an essential nutrient since the 1920s and is known to be part of, or a cofactor for, about 30 enzymes and proteins ${ }^{36}$. Some of the copperbinding enzymes and proteins and their known function are listed below.

\section{Intracellular}

- Cytochrome C oxidase (CCO) - electron transport

- Superoxide dismutase (SOD) - free radical detoxification

- Metallothionein - storage of copper

- Dopamine- $\beta$-hydroxylase - catecholamine production

- Tyrosinase (catechol oxidase) - melanin production

- Diamine oxidase - oxidative deamination

\section{Extracellular}

- Caeruloplasmin - ferroxidase, amine oxidase, copper transport

- Lysyl oxidase - crosslinking of collagen

- Albumin - copper transport

- Transcuprein - copper transport

- Amine oxidase - oxidative deamination 
Association with this diverse selection of enzymes means that the function of copper in the body is likely to be similarly diverse and may include protection against oxidative and inflammatory damage, bone health, arterial compliance, haemostasis and maintenance of immune function.

Severe or clinically defined copper deficiency in humans in rare but there are concerns that marginal or sub-optimal copper status may in the long term precipitate various degenerative and inflammatory conditions ${ }^{36}$.

Dietary copper deficiency has long been associated with exaggerated inflammatory responses in both humans and experimental animals ${ }^{36}$. Several aspects of neutrophil, monocyte and T-cell function are impaired during copper deficiency ${ }^{39}$.

Copper is considered as an antioxidant in vivo but it also has pro-oxidant activity in vitro and accumulation of tissue copper may lead to oxidative stress. However, the EUfunded FOODCUE Study - a collaboration between the Unité Maladies Métaboliques et Micronutriments (INRACRNH), France and the University of Ulster - found decreased susceptibility of red blood cells to peroxidation following supplementation of healthy men and women with copper. This decreased susceptibility occurred without changes in copper/zinc SOD activity and it was concluded that intake of copper as high as $7 \mathrm{mg} \mathrm{day}^{-1}$ has no pro-oxidant activity and may result in protection of red blood cells against oxidation ${ }^{40}$.

Some studies have suggested that atherogenesis occurs as a result of copper overload. This has been attributed to a direct effect on low-density lipoprotein-cholesterol (LDLC) oxidation by copper and it is suggested that this could be potentiated by a reduction in selenium, vitamin $\mathrm{E}$ and ascorbic acid concentrations ${ }^{41}$. This aspect has been studied within the MAFF programme (Table 3). No evidence of an effect of copper on LDL oxidation was found.

Shellfish, offal, nuts and whole-grain cereals provide rich sources of copper, but drinking water can make an important contribution, particularly when the water is supplied via copper piping. The current UK standard for the maximum concentration of copper in drinking water is $3 \mathrm{mgl}^{-1}$ (The Water Quality Regulations, 1989). It was based on an EC Directive (EC Directive 80/977), which has since been superseded by directive 98/83 on the quality of water intended for human consumption, that sets a limit of $2 \mathrm{mgl}^{-1}$. This Directive has not yet been implemented in the UK. The US Environmental Protection Agency has set a guideline of $1.3 \mathrm{mg} \mathrm{l}^{-1}$ and the World Health Organization (WHO), $2.0 \mathrm{mgl}^{-1}$. The estimated average daily dietary copper intake from the UK Total Diet Studies is just under $1.8 \mathrm{mg}$ or $0.03 \mathrm{mg} \mathrm{kg}^{-1}$ for an adult weighing $60 \mathrm{~kg}^{42}$.

The average daily copper intakes from diets in developed countries are said to be between 0.6 and $1.6 \mathrm{mg}^{37}$. The Dietary and Nutritional Survey of British Adults $^{21}$ indicated that the mean copper intake was
$1.59 \mathrm{mg} \mathrm{day}^{-1}$ in men and $1.23 \mathrm{mg} \mathrm{day}^{-1}$ in women. In the diet and nutrition survey of children aged 4-18 years, average copper intakes were $0.88 \mathrm{mg} \mathrm{day}^{-1}$ and $0.75 \mathrm{mg}$ day $^{-1}$ in boys and girls, respectively ${ }^{43}$.

It has been suggested that vegetarian diets generally contain higher quantities of copper, ranging from 2.1 to $3.9 \mathrm{mg}$ per day ${ }^{44}$. However, the average intake reported from the duplicate diet survey of vegetarians conducted in the UK was $1.3 \mathrm{mg}$ per day ${ }^{45}$.

Zinc and copper can interact, with high concentrations of one element inhibiting the absorption of the other. Both elements have similar electron configurations and form similar coordination complexes in aqueous solution, and hence compete for absorptive pathways. Copper has been shown to be involved in selenium metabolism and a deficit of copper can result in a reduction in the activities of multiple selenoenzymes ${ }^{46}$. The mechanisms underlying this effect of copper are not yet well understood.

Despite an increased understanding of the role dietary copper plays in human physiology and the potential contribution of sub-optimal copper status to the aetiology of several chronic diseases, satisfactory methods for the accurate diagnosis of sub-optimal copper status in humans have yet to be established. Although overt copper deficiency is often accompanied by changes in a variety of functional indices of copper status, the application of such indices (e.g. specific activity of erythrocyte superoxide dismutase, leucocyte or platelet cytochrome $\mathrm{C}$ oxidase and serum caeruloplasmin) to suboptimal copper status in humans has met with very limited success. Determinations of the activity of other copper metalloenzymes - such as skin lysyl oxidase and serum dopamine- $\beta$-monooxygenase, peptidylglycine $\alpha$ amidating monooxygenase and diamine oxidase - have recently been suggested as alternative, sensitive functional indices of human copper status. Until a sensitive method for the assessment of copper status is available, it remains uncertain whether sub-optimal copper status is prevalent in human populations and poses a risk to longterm human health ${ }^{47}$.

The Recommended Nutrient Intake (RNI) for adults (based on balance data) was set at $1.2 \mathrm{mg}$ per day ${ }^{1}$. The USA National Research Council has given the level of copper intake that is safe and adequate as $1.5-3.0 \mathrm{mg}$ day $^{-1}$ for adults ${ }^{48}$. The WHO has established the upper limit of the safe range as $12 \mathrm{mg}$ of copper per day for adults.

As yet there are insufficient data available upon which to review the DRVs or to determine the optimal intake.

\section{Contribution made by the MAFF programme}

As can be seen from Table $3^{35-38}$, a number of the research questions referred to above are being addressed by projects funded within the MAFF programme. However, important questions still remain unanswered, and priorities were identified and submitted to MAFF as part of the 
Table 2 Research priorities for folate

\section{MAFF programme objective}

1. To understand the links between Optimal Nutrition Status and the maintenance of good health

\section{Develop accurate measure of bioavailability from foods:}

(i) measure the fraction of ingested

nutrients which meets functional demands

in target tissues

(ii) develop functional markers of status

for each micronutrient, or group of micronutrients
Summary of the further research requirements

Neural tube defects (NTDs):

- There is need to determine if there are any genetic polymorphisms that do not respond to folic acid. There is also a need to look for and study the effect of polymorphisms on folate bioavailability and metabolism

Cardiovascular disease (CVD).

- There is need to determine if folate/folic acid is protective against CVD and, if so, whether it is working through homocysteine or other mechanisms?

- The use of some intermediate markers of CVD, e.g. brachial artery dilation, reduction of plaque, reduction of stenosis of arteries, should be used in some of the existing epidemiological studies so that earlier results might be obtained. FSA research projects could investigate the use and outcome of these markers

\section{Cancers:}

- There is need to determine if folates are protective against certain cancers - especially colorectal, cervical and breast cancers - and, if so, by what mechanism(s). Investigate whether there is evidence for a role for folate in the pre-malignant process, e.g. hypomethylation, misincorporation and strand breaks of DNA

Neurological and neuro-psychiatric disorders.

- There is need to determine if folates have a role to play in neurological and neuro-psychiatric disorders including Alzheimer's disease and, if so, by what mechanism

- Investigate the response of cells and tissues to high levels of folic acid, i.e. to unmetabolised folic acid, especially to masking of vitamin $\mathrm{B}_{12}$ deficiency

Future research needs to:

- improve the techniques for measurement of folates in body tissues and blood, so that the bioavailability of food folates can be measured and concentrations of folate in blood can be compared. In addition there is a need for Quality Assessment Schemes for measurement of folates and homocysteine (note: there is a scheme for homocysteine but not all laboratories have joined):

- investigate the influences that the form of dietary folate, food composition (especially fibre and phytic acid levels), food processing, food storage and preparation have on folate bioavailability. This will help establish how food folates can be enhanced, and what the most appropriate food for fortification is, in order to give maximum bioavailability of the added folate;

- investigate the impact of physiological state, diseases, particular genetic mutations and drugs on the bioavailability of different folates;

- determine the relative effectiveness of synthetic versus natural folates in homocysteine lowering;

- determine the effect of high levels of folic acid as fortificant or supplement on the absorption and metabolism of other nutrients, for example zinc

Homocysteine is currently the only marker that fits the criteria of a functional marker. If this measure is to be used as the functional marker for folate status associated with least risk of CVD, future research needs to determine: 
(iii) use human intervention studies to determine dose-response relationships against tissue function

(iv) understand the nature and extent of inter-individual variations, so as to identify an optimal nutrient intake for the whole population
- the cut-off values for plasma homocysteine;

- how the cut-off values vary with genetic variance;

- other specific functional markers for folate for specific diseases, e.g. CVD, cancers and neurological and neuro-psychiatric dysfunction. One option being investigated is endothelial cell damage, e.g. brachial artery dilation, as a functional indicator of homocysteine-related risk. If such markers are found to be useful, they need to be readily measurable on a population basis;

- the relative effect of folate, vitamin $B_{12}$ and vitamin $B_{6}$ in lowering homocysteine levels in blood

\section{There is need for:}

- dose-response studies and it has been recommended that a spectrum of doses between 200 and $2000 \mu \mathrm{g}$ folic acid per day be investigated;

- data from the four age bands of the National Diet and Nutrition Survey (NDNS) could be investigated to obtain a family of parallel curves of folate intake with folate status. The analyses for those aged 65 years or over have been produced by Bates et al. ${ }^{34}$. Vitamin $\mathrm{B}_{12}$ and vitamin $\mathrm{B}_{6}$ will need to be taken into account

The following were identified at the Review Workshop as being important factors to consider when planning intervention studies:

- target population - age effects, genotype effects, disease groups, drug interactions;

- dose - minimum amount of folates/folic acid needed to achieve desired change in functional marker (e.g.

homocysteine), maximum amount to cause adverse effects, and optimal levels of folic acid/ $\mathrm{B}_{12} / \mathrm{B}_{6}$;

- food issues - matrix effect, fortificant (type, vehicle), whole diet (inhibitors, enhancers), supplements and combined effects of natural, fortificant and supplement folates/folic acid;

- intermediate endpoint markers of reduced risk of disease - for CVD (e.g. endothelial function), for cancers (e.g colonic polyps), for colorectal cancer, for neurological dysfunction (e.g. cognitive tests)

Studies with large numbers are needed to investigate the effectiveness of each route of intervention (natural food folates, fortified food folates/folic acid, folic acid supplements) to increase the folate status of women as a means of protection from NTDs

\section{Future research needs to:}

- focus on describing the shape of the dose-response curve (between folate/folic acid intakes, plasma homocysteine levels and cardiovascular disease) in order to determine a reference range for plasma homocysteine levels in different population groups;

- determine how this optimal plasma homocysteine level relates to folate status (measured as plasma or red blood cell folate) and whether it varies in those with genetic or metabolic abnormalities or disease;

- carry out nationally representative population studies that measure folate intake (natural and fortified foods and supplements), and provide measures of folate status including plasma homocysteine and health/disease markers. Such studies might be included in the Government's National Diet and Nutrition Survey programme of nationally representative population samples. Analyses of the NDNS of people aged 65 years and over have been carried out $^{34}$ but future studies, e.g. NDNS of people aged 18-64 years, due to begin in 2000 , could ensure that relevant data are collected 
Table 3 Copper: achievement of MAFF programme objectives

\section{Programme objectives \\ 1. To understand the links between \\ Optimal Nutrition Status and the}

maintenance of good health

\section{Develop accurate measure of}

\section{bioavailability from foods:}

(i) measure the fraction of

ingested nutrients which meets

functional demands in target tissues

(ii) develop functional markers of status

for each micronutrient,

or group of micronutrients
References

Two associated projects (AN0509, AN0515) have investigated the effects of low, medium and high intakes of Cu on metabolic perturbations that might increase the risk of cardiovascular disease (adenosine diphosphate (ADP)-stimulated platelet aggregation, plasma lipoproteins (total, high-density lipoprotein-cholesterol (HDL-C) and LDL-cholesterol) and triglycerides). Neither dietary Cu levels of $0.7-6.0 \mathrm{mg}$ day $^{-1}$ nor apoE genotype was found to have a significant effect on any of these risk factors. With funding from non-MAFF sources, the contractors also investigated the effects of these low, medium and high intakes of $\mathrm{Cu}$ on risk factors for bone health. Bone metabolism was found to be affected significantly by dietary $\mathrm{Cu}$ intake at low intake $\left(0.7 \mathrm{mg} \mathrm{day}^{-1}\right)$, compared with medium and high intakes

Another project (AN0511) investigated the effect of Cu supplementation on oxidation processes (on LDL-C and native DNA in white blood cells). Copper supplementation did not affect LDL susceptibility to oxidation and there was no significant effect on DNA damage (using the comet assay)

AN0509 and AN0515 had, as secondary aims, study of the use of rare earth elements (REEs) as non-absorbable faecal markers for $\mathrm{Cu}$ absorption, using stable isotopes, and examination of the interaction between dietary fructose and $\mathrm{Cu}$.

The average apparent absorption of the ${ }^{65} \mathrm{Cu}$ dose was found to be significantly higher between the low $(0.7 \mathrm{mg}$ Cu per day) and both the high ( $6.0 \mathrm{mg}$ Cu per day) and medium ( $1.6 \mathrm{mg}$ Cu per day) dietary intake levels, whereas there was no significant difference between the medium and high intakes. Fructose had no effect on apparent absorption in all dietary significant difference between the medium and high intakes. Fructose had no effect on apparent absorption in all dietary
groups. The contractors concluded that an extrinsic label of ${ }^{65} \mathrm{Cu}$ can be used to measure $\mathrm{Cu}$ absorption from foods or meals using a faecal monitoring technique ${ }^{37}$. The results from these projects suggest that $\mathrm{Cu}$ homeostasis is mediated by both apparent $\mathrm{Cu}$ absorption and excretion. During the low-Cu diet the efficiency of absorption increased and endogenous losses were decreased compared with both the medium- and high-Cu diets. True absorption was found to be unaffected by dietary $\mathrm{Cu}$ intake

Two other associated projects (AN0548, AN0549) are determining the absorption of $\mathrm{Cu}$ (as well as $\mathrm{Fe}$ and $\mathrm{Zn}$ ) using stable isotopes, and luminal disappearance from three main types of diet consumed in the UK: (a) containing red meat, (b) containing poultry and fish and (c) vegetarian. The three diet types will each be consumed by 30 women $(90$ meat, (b) containing poultry and fish and (c) vegetarian. The three diet types will each be consumed by 30 women $(90$
in total) aged 18-40 years. These data will be used to make comparisons between the estimated dietary bioavailability in total) aged $18-40$ different diets
for the differ

AN0509 and AN0515 measured a range of putative indices of Cu status in the dietary intervention study: serum copper, immunoreactive caeruloplasmin, caeruloplasmin activity; erythrocyte $\mathrm{Cu} / \mathrm{Zn}$-superoxide dismutase; erythrocyte, plasma immunoreactive caeruloplasmin, caeruloplasmin activity; erythrocyte $\mathrm{Cu} / \mathrm{Zn}$-superoxide dismutase; erythrocyte, plasm and platelet glutathione peroxidase; and haemostatic parameters (fibrinogen, haemoglobin, mean cell haemoglobin concentration and haematocrit).
day $^{-1}$ ) after six weeks of intake 
(iii) use human intervention studies to determine dose-response relationships against tissue function

(iv) understand the nature and extent of inter-individual variations, so as to identify an optimal nutrient intake for the whole population
AN0511 has measured the effect of $\mathrm{Cu}$ supplementation on the following putative Cu status markers: SOD activity in erythrocytes and lymphocytes; CCO activity in lymphocytes and platelets; plasma caeruloplasmin (Cp) protein and activity; diamine oxidase (DAO); glutathione peroxidase. The only effect was with DAO: in the total group and in both males and females separately, serum DAO activity increased in each separate Cu supplementation regimen. The contractors report that DAO has the potential to be a sensitive marker of $\mathrm{Cu}$ status, but that there is a need for more work to determine the specificity of DAO as a putative $\mathrm{Cu}$ index and the possible risks/benefits of high/low serum DAO activity. The contractor also reported that the insensitivity of the other putative indices of Cu status (SOD, CCO and $\mathrm{Cp}$ ) to low-dose Cu supplementation was confirmed, and recommended that future studies investigating the effect of $\mathrm{Cu}$ on human health must make provision to assess DAO activity or other novel markers for Cu status

Establishing a set of functional markers capable of responding to small changes in body Cu status following periods of $\mathrm{Cu}$ depletion and repletion is the objective of AN0553. The study will attempt to clarify the relative sensitivity of selected immunological, oxidative, haemostatic and bone measures in volunteers depleted in Cu by the administration of the $\mathrm{Cu}$ antagonist zinc, followed by repletion with $\mathrm{Cu}$ supplements

AN0509 and AN0515 used a residential, longitudinal dietary intervention study (12 healthy male volunteers) to investigate the effects of low $\left(0.7 \mathrm{mg}_{\text {day }}{ }^{-1}\right)$, medium $\left(1.6 \mathrm{mg} \mathrm{day}^{-1}\right)$ and high $\left(6.0 \mathrm{mg} \mathrm{day}^{-1}\right)$ intakes of dietary $\mathrm{Cu}$ over 8-week periods (see above for results)

AN0511 used a dietary intervention in 24 free-living healthy volunteers (12 females and 12 males) to investigate the effect of $\mathrm{Cu}$ supplementation on oxidation processes (see above for results)

AN0553 is using 20 healthy men (aged 18-45 years) to determine small changes in body Cu status following 12-week periods of $\mathrm{Cu}$ depletion (using $50 \mathrm{mg} \mathrm{Zn}$ supplementation per day) and repletion (using $3 \mathrm{mg} \mathrm{Cu}$ supplementation per periods of Cu depletion (using $50 \mathrm{mg} \mathrm{Zn}$ supplementation per day) and repletion (using $3 \mathrm{mg}$ Cu supplementation per
day), interspersed with a 2-week washout period (zinc washout phase). The study will provide data on biochemical and physiological systems that are most likely to become limiting during periods of sub-optimal Cu status

The three studies in the AN05 programme investigating the effect of low, medium and high dietary Cu intakes and supplementation with $3 \mathrm{mg}$ and $6 \mathrm{mg}$ Cu per day in humans have information on the inter-individual variations in absorption. However, all of these studies include relatively small numbers of subjects

AN0511 - The effect of copper supplementation on measures of lipoprotein oxidation and DNA oxidant damage. University of Ulster, 1994-1998

AN0509/AN0515 - Metabolic and adaptive responses to different dietary intakes of copper. IFR and Central Science Laboratory (CSL) Norwich, 1994-1998.

AN0548/AN0549 - The bioavailability of iron, zinc and copper in meat-containing and vegetarian diets in the UK. IFR and CSL Norwich, 1998-2001 (Food Standards Agency project reference N05014/N05015). AN0553 - The development of functional markers of optimal nutritional status for copper. University of Ulster, 1998-2001 (Food Standards Agency project reference N05019). 
work conducted by the British Nutrition Foundation (Table 4).

\section{Iron}

Table $5^{49-56}$ lists the projects concerning iron conducted within the MAFF programme and the contributions these projects have made to MAFF's programme objectives.

The nutritional need (essentiality) for iron in living organisms is derived from the central role that it plays in the energy metabolism of living cells. Iron is a transition metal and can take part in redox processes by undergoing reversible valency changes, such as reduction by an organic substrate and re-oxidation by oxygen. It can also bind oxygen either on its own or as part of a complex. Ionic iron is an active promoter of free-radical reactions, and is toxic to living cells. Within the normal range of intakes, the body can convert absorbed iron into a bound 'safe' form. In humans, serum iron is bound to transferrin, and most body iron is present as iron porphyrin complexes (haemoglobin, myoglobin and haem-containing enzymes) $)^{57}$.

Iron-deficiency anaemia (IDA) is anaemia caused by lack of iron in the body and iron-deficient erythropoiesis is an impairment in iron supply to the bone marrow in the absence of storage iron that may occur with haemoglobin levels still in the reference range ${ }^{57}$.

The major consequences of iron lack include defects in psychomotor development in infants ${ }^{58-60}$, impaired educational performance in schoolchildren ${ }^{61}$, increased perinatal morbidity ${ }^{62}$ and impaired work capacity ${ }^{63}$. Few if any of the relevant investigations have demonstrated these abnormalities in the absence of anaemia ${ }^{64}$. Iron is an essential component of brain growth and is required not only for cell differentiation but also for protein synthesis, hormone production and fundamental aspects of cellular energy metabolism and functioning ${ }^{60}$. Iron is essential for the proper production and catabolism of several neurotransmitters and for other aspects of brain functioning that are not strictly related to developmental stage. It is now recognised that even modest iron deficiency can result in impaired learning and this can occur even in the absence of overt anaemia ${ }^{46}$.

The pro-oxidant role of iron is likely to be increased where iron overload occurs and iron is present in plasma and tissue in 'free' or abnormal forms. There is no physiological mechanism for excretion of excess iron, so the absorption of excess iron can lead to fatal storage iron accumulation. The main target organs for iron-induced tissue damage are the heart, endocrine glands and the liver ${ }^{57}$.

In vitro studies show that iron can promote lipid peroxidation and the breakdown of tissue integrity. This raises the possibility that, as a pro-oxidant, iron may play a part in the pathogenesis of a range of disorders, in addition to its known effects in human iron-overload disease ${ }^{57}$.
Some studies suggest that iron acts as a pro-oxidant to increase the risk of colorectal cancer ${ }^{65,66}$. However, a study by Tseng et al. ${ }^{67}$ that examined the effects of dietary iron on colorectal adenoma recurrence in humans concluded there was no clear evidence that recent dietary iron intake increases the risk of colorectal adenomas.

Iron has been found to bind to specific intracellular iron-binding proteins, changing their conformation and thus their ability to bind to iron-regulatory elements that are located at untranslated regions on mRNA. Depending on whether this makes stem-loop structures on mRNA more or less stable, protein synthesis will be repressed (e.g. ferritin) or suppressed (e.g. transferrin receptor). Thus, iron can directly act as a translation factor and regulate iron metabolism ${ }^{46,68}$.

The most important sources of iron are those foods that are not only rich in iron but also eaten in significant quantities, and from which iron is reasonably well absorbed, e.g. red meats. The major sources in Britain in practice are cereal products (approx. 50\%), meat and meat products (approx. 18\%) and vegetables (approx. 16\%). In the UK, all wheat flour, except wholemeal flour and some speciality flour, is compulsorily fortified with iron at $1.65 \mathrm{mg}$ per $100 \mathrm{~g}$. (The regulations also specify the particle size and solubility of added iron to ensure good bioavailability.) In addition, many breakfast cereals are voluntarily fortified with iron (most now contain about $6 \mathrm{mg}$ per $100 \mathrm{~g}$ ), and infant formulas and many other infant foods are fortified ${ }^{57}$.

Dietary iron consists primarily of non-haem iron. Lean meat contains $30-70 \%$ of its total iron as haem ${ }^{69}$. In industrialised countries only $10-15 \%$ of iron intake is as haem iron from meat products. About $6 \%$ of iron intake in the UK is fortification iron ${ }^{70}$. Assessment of dietary iron intake relies on good food composition data, which should include haem and non-haem iron. The data in food composition databases for total iron are comprehensive but as yet there are no published data on haem and nonhaem iron; the FSA is currently funding method development work on haem/non-haem iron in its Dietary Surveys and Nutrients in Food research programme.

The 1991 DRVs for iron were estimated from information on mean physiological requirements for different groups in the UK population, assuming dietary availability to be $15 \%{ }^{1}$. Each day the adult male requires about $1 \mathrm{mg}$ to replace that which is lost in epithelial cells, gut secretions, urine and skin. In menstruating women this can increase to about $1.4 \mathrm{mg}$ per day ${ }^{70}$. The current RNI for iron in the UK for men and for women over 50 years is $8.7 \mathrm{mg} \mathrm{day}{ }^{-1}$; for younger women the RNI is $14.8 \mathrm{mg}$ day $^{-1}$. The Dietary and Nutritional Survey of British Adults ${ }^{21}$ indicated that the average intake in men was well above the RNI at $14.1 \mathrm{mg}$ day $^{-1}$. However, intakes in women were lower, particularly in the younger age groups: $11.8 \mathrm{mg} \mathrm{day}^{-1}$ in $16-24$ year olds, $11.1 \mathrm{mg}^{-1}$ day $^{-1}$ in 25-34 year olds and $12.9 \mathrm{mg} \mathrm{day}^{-1}$ in 35-49 and 50-64 


\section{To understand the links between \\ Optimal Nutrition Status and the}

maintenance of good health

\section{Develop accurate measure of}

\section{bioavailability from foods:}

(i) measure the fraction of ingested nutrients

which meets functional demands in target tissues

(ii) develop functional markers of status for each micronutrient, or group of micronutrients

(iii) use human intervention studies to determine dose-response relationships against tissue function

(iv) understand the nature and extent of inter-individual variations, so as to identify an optimal nutrient intake for the whole population
- The Committee on Medical Aspects of Food Policy (COMA) Panel on Dietary Reference Values recommended further research on the significance of Cu deficiency in the UK in relation to cardiovascular disease, blood pressure and metabolism of neuroactive catecholamines and peptides. It also recommended further work on the functions of $\mathrm{Cu}$ in humans and the development of diagnostic indices of $\mathrm{Cu}$ status

Future research needs to:

- identify the functions of $\mathrm{Cu}$ (and other micronutrients) in the following target tissues: central nervous system (CNS) and brain, immune system, foetus, bone, skin, gut and liver;

- investigate the effects of marginal Cu deficiency on degenerative and inflammatory diseases including arthritis, cancer, bone health and ischaemic heart disease;

- further investigate the interaction between $\mathrm{Cu}$ and other micronutrients, e.g. Fe, $\mathrm{Zn}$ and Se;

- elucidate the basic defect in Menkes and Wilson diseases, both rare disorders, to provide the opportunity for new approaches in the diagnosis and treatment of affected patients and permit novel insights into the cellular mechanisms of Cu homeostasis;

- explore the functional role(s) of $\mathrm{Cu}$ in regulating the activation of the transcription factors (e.g. Ace1, Amt1, Mac1) which bind to metal-responsive elements in eukaryotes

Future research needs to:

- determine the fundamental mechanisms controlling $\mathrm{Cu}$ absorption and its regulation. Much more work is required on up- and down- regulation of absorption and how this changes with age and physiological states;

- identify Cu-specific genotypes and to determine how these affect Cu bioavailability;

- investigate the mobilisation of $\mathrm{Cu}$ and body Cu pool sizes using stable and radio-isotopes;

- investigate the interactions with other nutrients, e.g. Fe, Zn, Se, vitamin $\mathrm{C}$ and sugars, at low and high levels of $\mathrm{Cu}$ intake

Future research needs:

- to find functional markers of Cu status for (a) bone health, (b) cognitive function, (c) immuno-competence (this is a high priority need)

- once functional markers are identified, to standardise procedures for measuring them;

- to carry out fundamental studies in animal and cell culture to examine the mechanisms involved;

- to carry out studies on dose-response, and the effect of age and sex on the specificity of identified markers, e.g. DAO and peptidylglycine alpha-amidating monooxygenase (PAM)

Future research needs to:

- have functional markers developed before intervention studies are carried out. Studies should also measure plasma $\mathrm{Cu}$, caeruloplasmin, $\mathrm{Cu}$ enzymes, e.g. DAO and PAM, and isotope disappearance;

- focus on vulnerable groups, e.g. pregnant teenagers and young children;

take into account Cu content of drinking water;

- carry out studies to confirm safe upper levels of Cu intake

Future research needs to:

- use data collected in the NDNS programme for further analyses to explore the inter-individual variations in Cu intake and status measurements 
Table 5 Iron: achievement of MAFF programme objectives

\section{Programme objectives \\ 1. To understand the links between \\ Optimal Nutrition Status and th \\ maintenance of good health}

\section{Develop accurate measure of} bioavailability from foods:

(i) measure the fraction of

ingested nutrients which

meets functional demands in

target tissues
Achievements of individual projects

References

AN0507 studied the pro-oxidant role of iron in the human colon. Faecal iron increased significantly during the period of supplementation and returned to baseline within 2 weeks. The concentration of weakly bound iron in faeces (approx. $1.3 \%$ of total faecal iron) increased from $60 \mu \mathrm{moll}^{-1}$ before to $300 \mu \mathrm{moll}{ }^{-1}$ during supplementation, and the production of free radicals increased significantly (approx. 40\%). Higher carbohydrate diets were associated with reduced free radical generation. It was concluded that unabsorbed dietary iron may increase the production of free radicals in the colon to a level that could cause mucosal cell damage or increased production of carcinogens

AN0513 investigated the effects of co-supplementing healthy volunteers with iron and vitamin C on levels of platelet function and LDL oxidisability and antioxidant status. Co-supplementation favoured an antioxidant environment with no evidence for significant effects being found. The same contractors have also investigated the levels of oxidative damage in white blood cells under two conditions of co-supplementation

It has been shown that the relationship between iron intake and serum ferritin concentration is improved by taking into consideration food source and vitamin C intake (AN0502)

In AN0513, the intake of iron with two levels of ascorbic acid increased the levels of serum-bound iron but not haemoglobin; the level of serum-bound iron was dependent on the level of vitamin $\mathrm{C}$ supplementation. The lower level of supplementation $\left(60 \mathrm{mg} \mathrm{day}^{-1}\right.$ ) produced a steady increase that was significant after 12 weeks, whereas the higher level $\left(260 \mathrm{mg} \mathrm{day}^{-1}\right)$ produced a significant increase after 6 weeks, which decreased towards the initial levels after 12 weeks

Two pilot studies (AN0539 and AN0540) concerned the development of simple and accurate methods for determining mineral (iron, calcium, magnesium and zinc) absorption (luminal disappearance) from whole diets using stable isotopic extrinsic labels and rare earth faecal markers (REEs) as quantitative faecal markers. The excretory pattern of the iron isotopes and the REEs was very simiar, suggesting that the RE, dysprosim, can act as a quantitative faecal marker isotopes and the REEs was very similar, suggesting that the REE, dysprosium, can act as a quantitative faecal marker
for iron absorption

AN0541 and AN0542 developed a plasma appearance method to measure the absorption of iron fortification compounds and assessed the bioavailability of the fortificants used in cereal-based foods. The results were compared with those obtained from faecal monitoring. The contractors concluded that: 'Plasma appearance of stable isotopes may be a suitable method for absorption measurements when small oral doses $(3 \mathrm{mg})$ of labelled iron are used. Absorption measured using plasma appearance of iron tended to overestimate absorption in some cases probably because of natural increases in plasma iron during the study. Serum appearance of unlabelled iron may be a useful method for measuring relative absorption of therapeutic doses of iron but is not suitable for measuring absorption of dietary amounts. Serum appearance of reduced iron and ferric polymaltose indicated that these forms are not as well absorbed as ferrous sulphate'

The same projects also investigated the relative bioavailability of hydrogen-reduced iron powder in bread against a reference dose. The geometric mean absorption of the reference dose was $50 \%$ while the geometric mean absorption of the reduced iron was $65 \%$. An explanation was given for the unexpectedly high absorption of the reduced iron (probably due to the physico-chemical structure of the ${ }^{58} \mathrm{Fe}$-enriched reduced iron). The contractors concluded that reduced iron in bread has a relatively high availability for absorption
49 
(ii) develop functional markers of status for each micronutrient, or group of micronutrients

(iii) use human intervention studies to determine dose-response relationships against tissue function

(iv) understand the nature and extent of inter-individual variations, so as to identify an optimal nutrient intake for the whole population
AN0548 and AN0549 are using a combination of nutrient stable isotope and rare earth faecal marker methods to assess uptake of iron by females aged 18-40 years from mixed diets typical of those consumed in the UK (diets of high, medium and low bioavailability), and then relating the uptake to menstrual blood losses and changes in markers of iron status (haematological parameters and plasma ferritin)

The information from these studies is intended to feed into a parallel study (AN0551) that is building and testing a predictive model (algorithm) for the bioavailability of iron from mixed diets. The contractor's aim is to develop a relatively simple and inexpensive method for the assessment of mineral availability (iron, copper and zinc) from compositional data (minerals and inhibitors and promoters of iron absorption) of foods and a rapid human test (serum iron concentration), without the use of isotopes

None of the MAFF studies included development of functional markers of status for iron

AN0507 used two biomarkers of precancerous change in the animal studies: the rate at which the mucosal cells divide and the proportion of dividing cells close to the gut surface. In the human study, the production of free radicals in faeces in vitro was explored. The contractor was unable to measure DNA damage in humans because the colonocytes isolated from the faeces were too badly damaged to be useful in the assessment of potential oxidative DNA damage caused by excess iron in the large intestine

AN0513 used growth of mouse 3T3 fibroblasts to investigate the potential toxicity of various supplemental concentrations of $\mathrm{Fe}$ in studies of mouse and liver and plasma iron stores in the guinea pig studies. In the human studies, they used serum-bound iron, platelet function and LDL oxidisability

AN0502 investigated the influence of micronutrient supplementation (including $12 \mathrm{mg}$ of iron per day) on growth and psychological performance in school children (13-14 years). There were significant changes in status measurements over the 16-week study period, irrespective of supplementation, and these changes were markedly influenced by the initial status of the subject. There was no effect of supplementation on performance in tests of intelligence

AN0507 used a human intervention study to investigate the effect of iron supplementation on free radical production in faeces. There was a strong correlation between the free-radical-generating capacity of faeces and the concentration of faeces. There was a strong correlation between the free-radical-generating capacity of faeces and the concentration of 'free' iron within the faeces throughout the study

AN0513 included a human intervention study to investigate the effect of co-supplementation with iron and vitamin C

Many of the studies in the AN05 programme investigating the bioavailability of food iron and fortificant iron in humans have information on the inter-individual variations in absorption. Those studies that include iron supplements may also contribute information on the nature and extent of inter-individual variations in response to supplementary iron.

However, all of these studies include relatively small numbers of subjects

AN0502 - Development of biochemical and functional indices of nutritional status. IFR Norwich, 1991-1994.

AN0507 - Pro-oxidant effects of iron. IFR Norwich, 1994-1997.

AN0513 - Does iron supplementation together with vitamin C supplementation enhance bioavailability of iron in vivo? UMDS-Guy's Hospital Medical School, $1994-1997$.

AN0539/540 - Pilot study to develop a rare earth faecal marker technique for measuring the bioavailability of minerals in whole diets. CSL and IFR Norwich, 1996-1998.

AN0541/542 - Forms and bioavailability of iron in fortified cereal products. IFR and CSL Norwich, 1996-1998.

AN0548/549 - The bioavailability of iron, zinc and copper in meat-containing and vegetarian diets in the UK. IFR and CSL Norwich, 1999-2001 (Food Standards Agency project reference N05014/N05015). AN0551 - Test of a predictive model for the bioavailability of iron (plus Zn \& Cu) from mixed meals, using a simple in vivo human test for low doses of iron. Kings College London, 1998-2001 (Food Standards Agency project reference N05017). 
year olds (12.3 $\mathrm{mg} \mathrm{day}^{-1}$ in 16-64 year olds). Furthermore, intakes of iron were skewed, with median intakes for men and women being 13.2 and $10.0 \mathrm{mg} \mathrm{day}{ }^{-1}$, respectively. The median in the youngest age group of

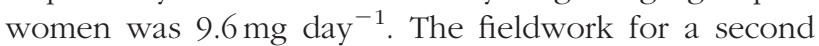
national survey of British adults was due to commence in the latter half of 2000. There is also evidence of low intakes of iron in other sections of the British population, e.g. preschool children ${ }^{71}$ and school-aged children ${ }^{43}$. In particular, iron intakes were low in up to half the older girls, and $14 \%$ of girls and 13\% of boys had low ferritin levels (a measure of iron status), suggesting low iron stores and an increased risk of anaemia. The proportion rose to $27 \%$ in the oldest group of girls.

Uptake of iron into the body is incomplete and variable, and the efficiency of absorption depends on a large number of dietary and host-related factors ${ }^{57}$. A broad range of dietary and physiological factors is known to either enhance or inhibit iron absorption.

- Dietary enhancers - organic acids, e.g. ascorbic, lactic, citric, malic and tartaric acids; fructose, sorbitol; alcohol; amino acids, e.g. cysteine, lysine, histidine.

- Physiological enhancers - iron-deficiency anaemia and iron-deficient states; fasting; pregnancy.

- Dietary inhibitors - tannins, polyphenols; phosphates, phytate; bran, lignin; proteins, e.g. egg albumen, egg yolk, legume protein; inorganic elements, e.g. Ca, Mn, $\mathrm{Cu}, \mathrm{Cd}, \mathrm{Co}$.

- Physiological inhibitors - iron overload; achlorhydria; copper deficiency.

Iron is absorbed by an active, saturable process, primarily in the duodenum, and is moved across the mucosal cell and serosal membrane into the blood where it is transported by transferrin to the cells or to the bone marrow for erythropoiesis. The body regulates iron homeostasis by controlling absorption and not by modifying excretion as with most other metals, i.e. absorption of iron is synonymous with bioavailability ${ }^{70}$. Iron absorption from a diverse diet has been assumed to be $15 \%{ }^{1}$. However, iron in diets containing little or no meat is less well absorbed. Unfortunately data do not exist to quantify this precisely.

Many studies have confirmed the enhancing effect of muscle tissue on iron absorption. Beef, lamb, chicken, pork and liver all have an enhancing effect that appears to be related to the high level of cysteine-containing proteins in these tissues. Their potential to chelate iron, and to reduce ferric iron to the more soluble ferrous iron, could explain the enhancing effect of cysteine-containing peptides on iron absorption ${ }^{70}$.

Ascorbic acid has the potential to facilitate the gastrointestinal absorption of non-haem iron ${ }^{72,73}$, possibly by converting $\mathrm{Fe}^{3+}$ (ferric) to $\mathrm{Fe}^{2+}$ (ferrous) ${ }^{74,75}$. However, although ascorbic acid can increase iron levels in these ways, the duration of this effect may be dependent on vitamin $\mathrm{C}$ intake, and vitamin $\mathrm{C}$ has been shown to have a lesser effect on iron metabolism in the longer term ${ }^{72,76}$. The enhancing effect of ascorbic acid is dose-related over the range $25-1000 \mathrm{mg}^{70}$.

Several studies have shown that calcium interferes with the absorption of non-haem iron. Studies by Hallberg and colleagues ${ }^{77}$ suggested that the effect is not located in the gastrointestinal tract but in the intestinal mucosal cells. Minihane and Fairweather-Tait ${ }^{78}$ have more recently reported on a study investigating the short-term and long-term effects of calcium supplementation on daily non-haem iron absorption and long-term iron status. They found that absorption of non-haem iron fell significantly with calcium supplementation (1200 mg day ${ }^{-1}$ ) in the short term, but in the long term supplementation with calcium did not reduce plasma ferritin concentrations in iron-replete adults consuming a Western-style diet containing moderate to high amounts of calcium in most meals ${ }^{78}$. Although much is known about individual dietary factors that affect iron absorption, it is apparent that results of iron absorption from single meals cannot be used to predict absorption from the whole $\operatorname{diet}^{51}$.

Awareness of the importance of iron in $\mathrm{O}_{2}$ transport and storage has led to the development of a number of laboratory methods to assess the size of various body iron compartments. Proper application of these techniques can provide a highly accurate and quantitative measure of body iron status ${ }^{64}$. Adequate iron nutrition can be defined as a normal haemoglobin concentration. However, haemoglobin has low sensitivity in identifying IDA due to the large overlap in values between normal and anaemic populations and low specificity due to the many causes of anaemia not due to iron lack, such as malaria, HIV infection, thalassaemia and chronic disease ${ }^{64}$. Other measures, e.g. serum ferritin, transferrin saturation, erythrocyte protoporphyrin, and mean corpuscular volume (MCV), are often included to improve the likelihood of identifying IDA. On the other hand, optimal iron nutrition should be regarded as sufficient body iron to avoid any limitation in tissue iron supply, termed irondeficient erythropoiesis. A variety of measurements have been used to identify this milder form of iron deficiency (iron status), including serum ferritin, transferrin saturation, erythrocyte protoporphyrin, MCV and, more recently, the concentration of the soluble fragment of transferrin receptor in serum. Recent studies indicate that the serum transferrin receptor is the preferred measurement, because enhanced synthesis of the transferrin receptor represents the initial cellular response to a declining iron supply. Moreover, unlike other methods, it is not affected by chronic inflammation or infection, which is often confused with iron deficiency ${ }^{64}$.

Currently, the only practical laboratory method for evaluating the size of the body iron store in epidemiological studies is the serum ferritin determination. More cumbersome methods such as quantitative phlebotomy, 
1. To understand the links between

\section{Optimal Nutrition Status and the}

maintenance of good health

\section{Develop accurate measure}

\section{of bioavailability from foods:}

(i) measure the fraction of ingested

nutrients which meets functional

demands in target tissues

(ii) develop functional markers of status for each micronutrient

or group of micronutrients
Future research needs to:

- investigate and evaluate the beneficial and adverse effects of iron food fortification and iron supplements, including a critical evaluation of the nutritional significance of the current UK iron fortification policy;

- determine whether the form of iron fortificant or supplement increases or decreases the beneficial or adverse effects;

- investigate the relationships between genetic and environmental factors in controlling iron stores;

- consider whether high iron stores are risk factors for conditions such as CVD, diabetes and cancer. If so, to investigate the role/mechanism of iron in cancer and CVD and determine whether this is modified by diet composition

- carry out prospective studies to confirm or better describe the associations observed in analyses of survey data, and to provide insights into the relationship between iron status and health

- critically evaluate the relative risks of iron deficiency and iron overload

Further research needs to:

- produce more data on the haem and non-haem iron content of foods, which should be included in food composition tables and databases:

- elucidate the mechanism of mucosal cell uptake and the regulation of iron absorption to maintain body homeostasis (the protein(s) and other factors in the brush border membrane that reduce ferric iron and subsequently carry iron into the mucosal cells need to be identified, and the role of iron-binding proteins and ligands in the movement of iron within the mucosal cell and subsequent transfer into the circulation requires clarification);

- study the potentially important gene-nutrient interactions, especially the influence of heterozygosity for genetic mutations on iron absorption;

- investigate how effective the mechanism for down-regulation of dietary iron absorption with increasing iron stores in healthy subjects is;

- investigate the influence of diet (dietary constituents) on iron absorption in different population groups, e.g. vegetarians, ethnic groups, the elderly and infants;

- further develop stable and radio-isotope methods (including intrinsically labelled foods) for measuring iron bioavailability from foods;

- study the interaction of iron with other micronutrients, e.g. $\mathrm{Cu}, \mathrm{Zn}$, vitamin $\mathrm{A}$ and iodine, both pre- and post-absorption into the body

Future research needs to:

- determine functional outcomes that are related to markers of iron status in the population e functional markers for psychomotor development in infants, educational performance/cognitive function in schoolchildren, work capacity and 'quality of life' in adults:

- develop experimental techniques to assess the full biological significance of free radical generation in faeces as a marker of colorectal carcinogenesis;

- standardise the method for measuring serum transferrin receptors and produce international standards to avoid the wide variation in the reported values as at present. (The current wide variation in the reported values is thought to reflect differences in immunological reagents and the materials used for standardisation.) This standardisation is essential if the proportion of people with low or absent iron stores is to be compared in different population groups;

- reach a consensus for the methods used in MAFF research projects to determine iron status. Standardise the assays used where these are not already standardised

Future research needs to:

include functional markers that relate to health and disease in intervention studies;

- carry out a dose-response iron supplementation study that includes various measures of iron status and pro-oxidant markers;

- investigate the long-term adaptive responses to different levels of iron intake

Future research needs to:

- explore the inter-individual variations of $\mathrm{Fe}$ status (using $\mathrm{Hb}$, ferritin and serum transferrin receptor) with reliable

dietary intake data studies to determine dose-response

(iv) understand the nature and extent of inter-individual variations, so as to identify an optimal nutrient intake for the whole population 
or more invasive methods such as bone-marrow examination for stainable iron, have been used to validate the serum ferritin as a simple quantitative measure of iron stores in otherwise healthy subjects. The majority of laboratory methods in current use are based on enzymelinked immunosorbent assay (ELISA), which requires only a few microlitres of serum or plasma. Standardisation of the assay of serum ferritin has largely been achieved ${ }^{79}$, but there remain problems with other assays, especially those for the serum transferrin receptor.

There is concern that high intakes of iron may play a role in the aetiology of cancer, particularly colon cancer ${ }^{80}$, and possibly coronary heart disease. Ionic iron is an active promoter of free-radical reactions and is toxic to living cells $^{51}$. It is hypothesised that in the large intestine, in combination with bacteria, excess iron may result in an increase in free radical generation. This may cause damage to mucosal cells or, more probably, increase the conversion of pro-carcinogens to carcinogens ${ }^{51}$. This is clearly an area of research that is very important in setting the upper limits of DRVs.

\section{Contribution made by the MAFF programme}

As can be seen from Table $5^{49-56}$, a number of the research questions referred to above are being addressed by projects funded within the MAFF programme. However, important questions still remain unanswered, and priorities were identified and submitted to MAFF as part of the work conducted by the British Nutrition Foundation (Table 6).

On 1 April 2000, responsibility for the MAFF nutrition research programmes including the Optimal Nutrition Status programme and the Dietary Surveys and Nutrients in Food programme transferred to the new Food Standards Agency.

\section{References}

1 Department of Health. Dietary Reference Values for Food Energy and Nutrients for the United Kingdom. Report on Health and Social Subjects No. 41. London: HMSO, 1991; $161-6$.

2 Buttriss J, Hughes J. A review of the MAFF optimal nutrition status programme. BNF Nutr. Bull. 2000; 25(1): 79-80.

3 Buttriss J, Bundy R, Hughes J. An update of vitamin K: contribution of MAFF-funded research. BNF Nutr. Bull. 2000; 25(2): 125-34.

4 Hughes J, Buttriss J. An update on folate and folic acid: contribution of MAFF-funded research. BNF Nutr. Bull. 2000; 25(1): 113-34.

5 Hughes J, Buttriss J. An update on copper: contribution of MAFF-funded research. BNF Nutr. Bull. 2000; 25(4): 271-80.

6 Bellamy MF, McDowell IFW. Putative mechanisms for vascular damage by homocysteine. J. Inherited Metab. Disord. 1996; 20: 307-15.

7 McDowell IFW, Ashfield-Watt P. Approaches to defining optimal folate intake for cardiovascular health. Nutr. Food Sci. 1997; 6: 215-7.

8 Bellamy MF, McDowell IF, Ramsey MW, Brownlee M, Bones
C, Newcombe RG, Lewis MJ. Hyperhomocysteinaemia after an oral methionine load acutely impairs endothelial function in healthy subjects. Circulation 1998; 98: 1848-52.

9 Still RA, McDowell IFW. Clinical implications of plasma homocysteine measurement in cardiovascular disease. J. Clin. Pathol. 1998; 51: 183-8.

10 Bellamy MF, McDowell IFW, Ramsey MW, Brownlee M, Newcombe RG, Lewis MJ. Oral folate enhances endothelial function in hyperhomocysteinaemic subjects. Eur. J. Clin. Invest. 1999; 29: 659-62.

11 McDowell IFW. Homocysteine and cardiovascular disease. J. Int. Fed. Clin. Chem. 1998; 10: 73-6.

12 Doshi SN, Goodfellow J, Lewis MJ, McDowell IF. Homocysteine and endothelial function. Cardiovasc. Res. 1999; 42 578-82.

13 McNulty $H$. Folate requirements for health in different population groups. Br. J. Biomed. Sci. 1995; 52: 110-9.

14 McNulty H. Folate requirements for health in women. Proc. Nutr. Soc. 1997; 56: 291-303.

15 Moat SJ, Bonham JR, Powers HJ. Circulating antioxidant enzyme activity is influenced by homocysteine. Netherlands J. Med. 1998; 52: S58.

16 Ashfield-Watt PAL, Knowles RM, Cale SB, Clark ZE, McDowell IFW. A practical dietary intervention lowers plasma homocysteine in hyperlipidaemic patients. Heart 1999; 81(Suppl. 1): 30.

17 Finglas PM, Wigertz K, Vahteristo L, Witthoft CM, Southon S, de Froidmont-Gortz I. Standardisation of HPLC procedures for the determination of naturally-occurring folates in food. Food Chem. 1999; 64: 245-55.

18 Cuskelly GJ, McNulty H, Scott JM. Low levels of folic acid fortification make a significant difference in folate status in young women: implications for the prevention of neural tube defects. Am. J. Clin. Nutr. 1999; 70: 234-9.

19 McNulty H, Cuskelly GJ, Ward M. Response of red cell folates to intervention: implications for folate recommendations for the prevention of neural tube defects. Am. J. Clin. Nutr. 2000; 71(5): 1308S-11S.

20 Department of Health. Folic Acid and the Prevention of Disease. Report on Health and Social Subjects No. 50. London: HMSO, 2000.

21 Gregory J, Foster K, Tyler H, Wiseman M. The Dietary and Nutritional Survey of British Adults. London: HMSO, 1990.

22 Ministry of Agriculture, Fisheries and Food (MAFF). National Food Survey. London: HMSO, 1998.

23 Scott JM. Folate and vitamin B12. Proc. Nutr. Soc. 1999; 58 441-8.

24 Scott JM, Weir DG. Folic acid, homocysteine and one-carbon metabolism: a review of the essential biochemistry. J. Cardiovasc. Risk 1998; 5(4): 223-7.

25 Graham IM, Daly LE, Refsum HM, Robinson K, Brattstrom LE, Ueland PM, Palma-Reis RJ, et al. Plasma homocysteine as a risk factor for vascular disease. The European Concerted Action Project. J. Am. Med. Assoc. 1997; 277: 1775-81.

26 Selhub J, Jacques PF, Wilson PW, Rush D, Rosenberg IH. Vitamin status and intake as primary determinants of homocysteine in an elderly population. J. Am. Med. Assoc. 1993; 270: 2693-8.

27 Clarke R. Homocysteine and cardiovascular disease. Overview. J. Cardiovasc. Risk 1998; 5(4): 213-5.

28 Clarke R, Collins R. Can dietary supplements with folic acid or vitamin B6 reduce cardiovascular risk? Design of clinical trials to test homocysteine hypothesis of vascular disease. J. Cardiovasc. Risk 1998; 5(4): 249-55.

29 Weisberg T, Tran P, Christensen B, Sibani S, Rozen R. A second genetic polymorphism in methylenetetrahydofolate reductase (MTHFR) associated with decreased enzyme activity. Mol. Genet. Metab. 1998; 64(3): 169-72.

30 Freudenheim JL, Marshall JR, Vena JE, Laughlin R, Brasure JR, Swanson MK, Nemoto T, Graham S. Premenopausal breast 
cancer risk and intake of vegetables, fruits, and related nutrients. J. Natl. Cancer Inst. 1996; 88(6): 340-8.

31 Clarke R, Smith AD, Jobst KA, Refsum H, Sutton L, Ueland PM. Folate, vitamin B12 and serum total homocysteine levels in confirmed Alzheimer disease. Arch. Neurol. 1998; 55 1449-55.

32 Kelly P, McPartlin J, Goggins M, Weir DG, Scott JM. Unmetabolized folic acid in serum: acute studies in subjects consuming fortified food and supplements. Am. J. Clin. Nutr. 1997; 65(6): 1790-5.

33 Sweeney MR, McPartlin J, Weir DG, Scott JM. Folic acid fortification of bread: effect of chronic consumption on unmetabolised folic acid in serum. Proc. Nutr. Soc. 2000; 59(OCA): 82A.

34 Bates CJ, Mansoor MA, van der Pols J, Prentice A, Cole TJ, Finch S. Plasma total homocysteine in a representative sample of 972 British men and women aged 65 and over. Eur. J. Clin. Nutr. 1997; 51(10): 691-7.

35 Harvey L, Majsak-Newman G, Fairweather-Tait SJ, Baker A, Cachman K, Flynn A, Lewis D, Crewes H. Effect of dietary copper intake on biochemical indices associated with copper metabolism. In: Roussel AM, Anderson RA, Favier AE, eds. Proceedings of the Tenth International Symposium on Trace Elements in Man and Animal, Evian, France, 2- 7 May 1999. New York: Kluwer Academic/Plenum Publishers, 2000; 959-60.

36 Turley E, McKeown A, Harvey LJ, Fairweather-Tait SJ, Crewes HM, Strain JJ. Assessing copper status - a review. Nutr. Food Sci. 1997; 6: 229-32.

37 Fairweather-Tait SJ. Bioavailability of copper. Eur. J. Clin. Nutr. 1997; 51(Suppl. 1): 24S-6S.

38 Crews HM, Baxter MJ, Lewis DJ, Havermeister W, Fairweather-Tait SJ, Harvey LJ, Majsak-Newman G. Multielement and isotope ratio determinations in foods and clinical samples using inductively coupled plasma-mass spectrometry. In: Trace Elements in Man and Animals - 9 Ottawa, Canada: NRC Research Press, 1997.

39 Lewis AJ. The role of copper in inflammatory disorders. Agents Actions 1984; 15: 513-9.

40 Rock A, Mazur A, Rayssiguier Y, Kehoe C, O'Connor JM, Bonham MP, Strain JJ. Effect of copper supplementation in middle aged people on plasma anti-oxidants and red blood cell oxidizability: FOODCUE Study. In: Roussel AM, Anderson RA, Favier AE, eds. Proceedings of the Tenth International Symposium on Trace Elements in Man and Animal, Evian, France, 2- 7 May 1999. New York: Kluwer Academic/Plenum Publishers, 2000; 475-6.

41 Olivares M, Uauy R. Copper as an essential nutrient. Am. J. Clin. Nutr. 1996; 63: 791S-6S

42 Ministry of Agriculture, Fisheries and Food (MAFF). 1994 Total Diet Study: Metals and Other Elements. Food Surveillance Information Sheet No. 131. London: MAFF, 1997.

43 Gregory J, Lowe S, Bates CJ, Prentice A, Jackson LV, Smithers G, Wenlock R, Farron M. National Diet and Nutrition Survey: Young People aged 4 to 18 years. London: The Stationery Office, 2000.

44 Gibson RS. Content and bioavailability of trace elements in vegetarian diets. Am. J. Clin. Nutr. 1984; 59: 1223S-32S.

45 Ministry of Agriculture, Fisheries and Food (MAFF). Duplicate Diet Study of Vegetarians - Dietary Exposure to 12 Metals and Other Elements. Food Surveillance Information Sheet No. 193. London: MAFF, 2001.

46 Lonnerdal B, Keen CL. New functions of trace elements. Scand. J. Nutr. 1999; 43(Suppl. 2): 25S-6S.

47 Strain JJ. Defining optimal copper status in humans. Concepts and problems. In: Roussel AM, Anderson RA, Favier AE, eds. Proceedings of the Tenth International Symposium on Trace Elements in Man and Animal, Evian,
France, 2-7 May 1999. New York: Kluwer Academic/ Plenum Publishers, 2000; 923-8.

48 National Research Council. Recommended Dietary Allowances. Washington, DC: National Academy Press, 1989.

49 Lund EK, Wharf SG, Fairweather-Tait SJ, Johnson IT. Oral ferrous sulfate supplements increase the free radicalgenerating capacity of feces from healthy volunteers. $\mathrm{Am}$. J. Clin. Nutr. 1999; 69(2): 250-5.

50 Rehman A, Collis CS, Yang M, Kelly M, Diplock AT, Halliwell $\mathrm{B}$, Rice-Evans $\mathrm{C}$. The effects of iron and vitamin $\mathrm{C}$ COsupplementation on oxidative damage to DNA in healthy volunteers. Biochem. Biophys. Res. Commun. 1998; 246(1): 293-8.

51 Fairweather-Tait SJ, Johnson IT, Wharf SG, Lund EK. Iron getting the balance right. Nutr. Food Sci. 1997; 6: 212-4.

52 Lund EK, Wharf SJ, Fairweather-Tait SJ, Johnson IT. The effects of dietary iron and phytate on cell proliferation and apotosis in rat large intestine. Gut 1996; 38(Suppl. 1): A19.

53 Wharf SG, Lund EK, Parker M, Johnson IT, Fairweather-Tait SJ. The feasibility of using exfoliated human colon cells to monitor the potential pro-oxidant effects of iron. In: Trace Elements in Man and Animals - 9. Ottawa, Canada: NRC Research Press, 1997.

54 Collis CS, Yang M, Peach SJ, Diplock AT, Rice-Evans C. The effects of ascorbic acid and iron cosupplementation on the proliferation of 3T3 fibroblasts. Free Radical Res. 1996; 25 : $87-93$.

55 Southon S, Wright AJA, Finglas PM, Bailey AL, Loughridge JM, Walker AD. Dietary intake and micronutrient status of adolescents: effect of vitamin and trace element supplementation on indices of status and performance in tests of verbal and non-verbal intelligence. Br. J. Nutr. 1994; 71: 897-918.

56 Fairweather-Tait SJ, Minihane AM, Eagles J, Owen L, Crews HM. Rare earth elements as nonabsorbable fecal markers in studies of iron absorption. Am. J. Clin. Nutr. 1997; 65(4): 970-6.

57 British Nutrition Foundation. Iron: Nutritional and Physiological Significance. London: Chapman \& Hall, 1995.

58 De Andraca I, Castillo M, Walter T. Psychomotor development and behavior in iron-deficient anemic infants. Nutr. Rev. 1997; 55: 125-32

59 Oski FA, Honig AS, Helu B, Howanitz P. Effect of iron therapy on behavior performance in nonanemic, irondeficient infants. Paediatrics 1983; 71: 877-80.

60 Beard J. One person's view of iron deficiency, development, and cognitive function. Am. J. Clin. Nutr. 1995; 62: 709-10.

61 Pollitt E. Iron deficiency and educational deficiency. Nutr. Rev. 1997; 55: 133-41.

62 Allen LH. Pregnancy and iron deficiency: unresolved issues. Nutr. Rev. 1997; 55: 91-101.

63 Levin HM. A benefit-cost analysis of nutritional programs for anaemia reduction. Res. Obs. 1986; 1: 219-45.

64 Cook JD. Defining optimal body iron. Proc. Nutr. Soc. 1999; 58: $489-95$.

65 Babbs CF. Free radicals and the etiology of colon cancer. Free Radical Biol. Med. 1989; 8: 191-200.

66 Weinberg ED. Roles of iron in neoplasia: promotion, prevention and therapy. Biol. Trace Element Res. 1992; 34: $123-40$.

67 Tseng M, Sandler RS, Greenberg ER, Mandel JS, Haile RW, Baron JA. Dietary iron and recurrence of colorectal adenomas. Cancer Epidemiol. Biomark. Prev. 1997; 6(12): 1029-32.

68 Klausner RD, Rouault TA, Harford JB. Regulating the fate of mRNA: the controls of cellular iron metabolism. Cell 1993; 72: $19-28$.

69 MacPhail AP, Charlton R, Bothwell TH, Bezwoda WR. Experimental fortificants. In: Clydesdale FM, Weimer KL, eds. Iron Fortification of Foods. New York: Academic Press, $1985 ; 55-75$. 
70 Hurrell RF. Bioavailability of iron. Eur. J. Clin. Nutr. 1997; 51(Suppl. 1): S4-S8.

71 Gregory J, Collins DL, Davies SW, Hughes JM, Clarke PC. National Diet and Nutrition Survey: Children aged $1 \frac{1}{2}$ to $4 \frac{1}{2}$ years. Vol. 1. Report of the Diet and Nutrition Survey. London: HMSO, 1995.

72 Cook JD, Watson SS, Simpson KM, Lipschitz DA, Skikne BS. The effect of high ascorbic acid supplementation on body iron stores. Blood 1984; 64: 721-6.

73 Hallberg L, Brune M, Rossander L. Effects of ascorbic acid on iron absorption from different types of meals. Studies with ascorbate rich foods and synthetic ascorbic acid given in different amounts with different meals. Hum. Nutr. Appl. Nutr. 1986; 40A: 97-113.

74 Baird IM, Walters RL, Sutton DR. Absorption of slow-release iron and effects of ascorbic acid in normal subjects and after partial gastrectomy. Br. Med.J. 1974; 4: 505-8.
75 Levine M. New concepts in the biology and chemistry of ascorbic acid. N. Engl. J. Med. 1986; 314: 892-902.

76 Hunt JR, Gallagher SK, Johnson LK. Effect of ascorbic acid on apparent iron absorption by women with low iron stores. Am. J. Clin. Nutr. 1994; 59: 1381-5.

77 Hallberg L, Rossander-Hulten L, Brune M, Gleerup A. Calcium and iron absorption: mechanism of action and nutritional importance. Eur. J. Clin. Nutr. 1992; 46: 317-27.

78 Minihane AM, Fairweather-Tait SJ. Effect of calcium supplementation on daily nonheme-iron absorption and long-term iron status. Am.J. Clin. Nutr. 1998; 68(1): 96-102.

79 Worwood M, Thorpe SJ, Heath A, Flowers CH, Cook JD. Stable lyophilised reagents for the serum ferritin assay. Clin. Lab. Haematol. 1991; 13: 297-305.

80 Wurzlemann JI, Silver A, Schreinemachers DM, Sandler RS, Everson RB. Iron intake and the risk of colorectal cancer. Cancer Epidemiol. Biomark. Prev. 1996; 5(7): 503-7. 